\title{
The Factors Impact on Employee Satisfaction in Work at Vietnamese Garment Enterprises
}

\author{
Hoang Thanh Tung*, Nguyen Thi Van Anh, Pham Thi Thuy Anh \\ University of Labour and Social Affairs, Hanoi, Vietnam \\ Email: *hoangthanhtung15@gmail.com
}

How to cite this paper: Tung, H.T., Van Anh, N.T. and Anh, P.T.T. (2019) The Factors Impact on Employee Satisfaction in Work at Vietnamese Garment Enterprises. Open Journal of Business and Management, 7, 666-679.

https://doi.org/10.4236/ojbm.2019.72045

Received: March 3, 2019

Accepted: April 5, 2019

Published: April 8, 2019

Copyright $\odot 2019$ by author(s) and Scientific Research Publishing Inc. This work is licensed under the Creative Commons Attribution International License (CC BY 4.0).

http://creativecommons.org/licenses/by/4.0/

\section{Open Access}

\begin{abstract}
This research is to identify and assess the factors that impact an employee's satisfaction in work. The company selected for this research is a leading garment company of the Vietnamese textile and garment industry. With the survey and analyzing the opinion of 318 workers, the research results indicated six groups of elements (variables) in work which have impacted on the staff's satisfaction: wages and welfare, working conditions, relations with superiors, relations with colleagues, training and promotion opportunities, nature of work. These six-factor groups were measured by 27 observed variables. The analysis and evaluation of factors affect the satisfaction of employees in order to contribute practically to the setting up and implementation of effective measures to enhance job satisfaction for employees, create motivate labor and bring the higher labor productivity.
\end{abstract}

\section{Keywords}

Employee Satisfaction, Factor Analysis, Job Satisfaction, Garment Enterprise, Human Resources Management

\section{Introduction}

In the context of global economic competition and international economic integration, almost enterprises consider human resources to be the most important tool to improve product competitiveness as well as company competitiveness. For enterprises in the garment industry, which is considered labor intensive, human resources are always a decisive factor for the existence and development of enterprises.

Garment enterprises in Vietnam are facing a difficult problem that is the situation of quite large labor fluctuation due to the lack of attachment between enterprises and workers. The competition in salaries, working conditions, prefe- 
rential regimes attracts employees among enterprises entice employees to quit their jobs and transfer jobs continuously. Currently the whole industry is facing labor fluctuations with the rate of annual labor fluctuations in garment enterprises about $25 \%$ - 30\%, even, in foreign-invested enterprises, this rate is up to $40 \%$ [1]. With a labor-intensive nature, retaining employees and stabilizing the personnel situation is the primary concern of the leaders. If the workers are satisfied with their work, they will love the work, stick with the enterprises, maximize their capacity and enthusiasm for the business, so the productivity and efficiency of employees will be higher, that help businesses not only exist but also develop in an environment more and more competitive. So what factors affect satisfaction in working of employees in the garment industry? How does each factor affect? Which factors can motivate employees to work better and more enthusiastically?

The paper focuses on analyzing the level of satisfaction and factors affecting the satisfaction of garment workers in their work, suggesting solutions to ameliorate the problems exist and enhance employee satisfaction in work. This is also the basis for managers in garment enterprises to adjust human resource administration policies, improve the competitiveness of enterprises in the period of international economic integration.

\section{The Basis of Theory, Model and Research Hypotheses}

\subsection{Basic of Theory}

One of the most complex areas faced by human resource managers is measuring and improving job satisfaction. There have been many scientific studies research the satisfaction and factors affecting the working satisfaction of employees.

According to Herzberg [2], the satisfaction of employees is the degree to which a worker loves his work or try his best to maintain the work, that is expressed by positive or negative perception about the different aspects of work that affect them.

Vroom, V. H. [3], in his study of job satisfaction, he focused on the role of workers at working place. He defines job satisfaction is a state in which employees have a clear and effective orientation to the work they undertake in the organization and really enjoy this work.

From Maslow [4], Adam [5] and McClelland [6], satisfaction, in general, will be achieved when the value received is greater than or equal to the expected value. On the basis of that theory, some researchers define satisfaction as the actual value (actual satisfaction state) that employees receive compared to the expected value (state of satisfaction expected) on work aspects such as salary, welfare, job nature, working relations or working conditions, etc.

Smith, Kendall, and Hulin [7] argue that employee satisfaction is reflected in the following five impact factors: job satisfaction; satisfied with wages; satisfied with training and promotion opportunities; satisfied with the supervision of leaders and satisfied with colleagues. 
According to Dung, T.K [8], job satisfaction of employees is defined and measured in two aspects: general satisfaction with work and satisfaction of the elements of work. The general satisfaction is the feeling when they are satisfied and happy with their needs they had set and achieve by the impact of themselves, other objective and subjective factors. Job satisfaction includes human needs achieved through the impact and effect of factors in the working environment.

In general, there are many different definitions of the job satisfaction of workers. Each researcher has its own view and explanation through their research works. In this study, the authors consider the satisfaction in work is the aggregate level of employee satisfaction with the components or aspects of the job. In other words, general satisfaction in work and satisfaction with the aspects of work are different variables and they are related to each other.

\subsection{Model and Research Hypotheses}

Inheriting and selecting a number of theoretical bases and scales of factors in previous studies, adjusting to suit the research objectives, the research model is designed based on a combination of factors that measure the satisfaction in work in the context of Vietnam as: 1) nature of work; 2) working conditions; 3) salaries and welfare; 4) training and promotion opportunities; 5) relations with superiors; 6) relations with colleagues; at the same time, combine the personal characteristics that measure the satisfaction in work of workers. The research model is as follows: (Figure 1 ).

Hypotheses for the proposed research model include:

$\mathrm{H1}$ : The nature of work has a positive impact on the general satisfaction in the work of employees.

$\mathrm{H} 2$ : Working conditions have a positive impact on satisfaction in the work of employees.

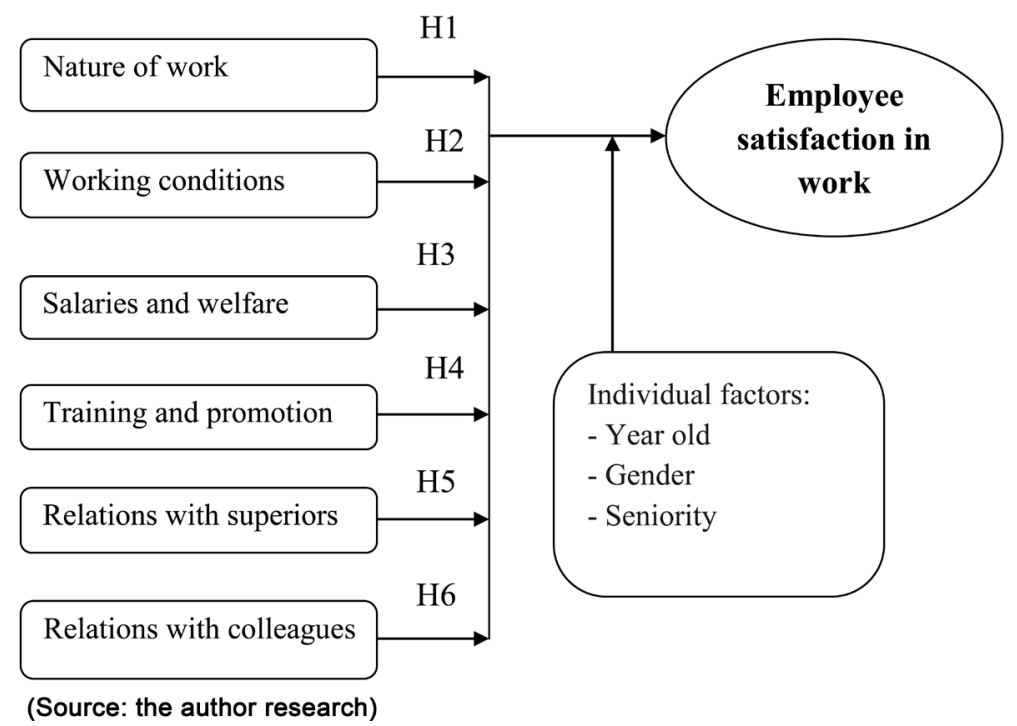

Figure 1. The proposed research model. 
H3: Salaries and welfare have a positive impact on the general satisfaction in the work of employees.

H4: Traning and promotion opportunities have a positive impact on the general satisfaction in the work of employees.

H5: Relations with superiors have a positive impact on the general satisfaction in the work of employees.

H6: Relations with colleagues have a positive impact on the general satisfaction in the work of employees.

\section{Research Method}

\subsection{Measure Variables and Select Research Samples}

The study was conducted on the basis of the combination of qualitative research and quantitative research. The first step, a qualitative research method is used to conduct preliminary research. The authors discuss with 2 groups of employees, each group of 5 people works in 5 different job positions. The discussion uses a set of preliminary scales with satisfaction factors in reference work from previous studies. The participants in the discussion were free to give their opinions on aspects of satisfaction in work. Preliminary study sample is $10(n=10)$. Preliminary research results are used to complete research questionnaires and research models

Quantitative research methods are conducted to collect employees' opinions about their satisfaction with current jobs. The questionnaire was set up based on preliminary research results and use Likert 5-level questions. The questionnaire consists of 29 observable variables, with each observed variable will be measured by 5 levels: 1, Strongly disagree; 2, Do not agree; 3, Normal; 4, Agree; 5, Very agree. Due to the limited time of the survey, the author used a convenient sampling method. The sample size was determined according to the rules of Comrey and Lee [9] and also referred to the rules of Trong, Hoang \& Mong Ngoc, Chu Nguyen [10]. With 29 observed variables necessary to conduct factor analysis, the minimum number of samples is $29 \times 5=145$ observation samples. With the point of view of collecting as many samples as possible to ensure the stability of the impact, based on the ability to collect samples, the authors decided to select the number of observation samples is $n=300$. To ensure the sample size, the authors have broadcasted 350 questionnaires, the number of questionnaires collected was 337, of which due to answering with a lack of information or a response not following the instructions or adding the answer, 19 votes were rejected; 318 valid votes used for analysis.

\subsection{Analysis of Research Data}

The research data after collected will be cleaned and analyzed with the support of SPSS 20.0 software with analytical techniques:

Descriptive statistics: Describe the characteristics of the sample according to the identified signs. 
Check the reliability of the scale (Cronbach's Alpha): This method evaluates the reliability of the scale by Cronbach's Alpha coefficient and removes the unsuitable variables. Variables whose correlation coefficient with the total variable is less than 0.3 will be rejected. The scale with Cronbach's Alpha coefficient over 0.6 is usable.

Factor Analysis EFA: Factor analysis EFA allows the compaction of multiple correlated variables into representative factors. Using the Kaiser-Meyer-Olkin (KMO) and Bartlett test to measure the fit of the research samples. Factor analysis is statistical significance if the KMO value $>0.5$ and the value of sig < 0.05 ; Factor loading must be $>0.5$; In case an observed variable uploads both factors, the loading factors must be different more than 0.3 and this observed variable is counted to the factor that it uploads the highest with the condition must satisfy the factor loading $>0.5$.

Correlation and Regression analysis: After extracting the representative factors, using the Pearson correlation coefficient method to evaluate the linear correlation relationship between the factors in the model. If the sig value is $<0.05$, the analytical result is statistically significant; correlation coefficients $>0$ represent variables with linear correlation. On that basis, the linear regression model was set up and the $\mathrm{R}^{2}$ coefficient adjusted to indicate the suitability of the established regression model.

Verify the differential impact of personal factor: Independent-Sample T-Test and One-Way ANOVA test will be used to consider the different influence of qualitative variables such as age, gender, seniority.

\section{Research Results}

\subsection{Introduction of Research Samples}

The researched organization is an enterprise in the garment industry with a large production scale. Enterprises have more than 11,000 employees, modern machinery and equipment, diversified production items, the brand also has a reputation in domestic and foreign markets. This enterprise has won the title of “Top 5" enterprises in Vietnam Textile and Garment industry

With 350 questionnaires broadcasted, 337 were collected, of which 318 valid votes were used for analysis. Some characteristics of the sample are described as follows: (Table 1).

Classifications by gender show a large disparity between men and women due to the characteristic of the garment industry. Among them, $22.6 \%$ are male and $77.4 \%$ are female. The age of workers concentrated from the age of $25-45$ accounted for $69.8 \%$. Working time at the company, the number of employees with working time from 1 - 5 years accounted for $34 \%$, from 5 - 10 years accounted for $43.4 \%$.

The results presented in Table 2 shows that: with the rating scale from 1 being the lowest to 5 being the highest, the score of employees satisfaction in work is 3.15 (average level); The highest satisfaction rating is satisfied with co-worker 
Table 1. Describe the research samples.

\begin{tabular}{cccc}
\hline Criteria & & Number & Percent (\%) \\
\hline \multirow{3}{*}{ Gender } & Man & 72 & 22.6 \\
& Feman & 246 & 77.4 \\
& Under 25 years old & 48 & 15.1 \\
Year old & From 25 to 35 years old & 120 & 37.7 \\
& From 36 to 45 years old & 102 & 32.1 \\
& Above 45 years old & 48 & 15.1 \\
& Under 1 year & 36 & 11.3 \\
Seniority & From 1 to 5 years & 108 & 34.0 \\
& From 5 to 10 years & 138 & 43.4 \\
& Above 10 years & 36 & 11.3 \\
\hline
\end{tabular}

Source: The data from the questionnaires.

Table 2. Statistical results of satisfaction level.

\begin{tabular}{ccccccc}
\hline \multirow{2}{*}{ Satisfaction } & \multicolumn{5}{c}{ Statistic } \\
\cline { 2 - 6 } & Sample Number & $\min$ & $\max$ & mean & Standard deviation \\
\hline Satisfaction in work & 318 & 1 & 5 & 3.15 & 0.664 \\
Satisfaction with the nature of work & 318 & 1 & 5 & 3.51 & 1.023 \\
Satisfaction with working conditions & 318 & 1 & 5 & 2.89 & 1.077 \\
Satisfaction with salaries and welfare & 318 & 1 & 5 & 2.34 & 0.991 \\
$\begin{array}{c}\text { Satisfaction with training and } \\
\text { promotion opportunities }\end{array}$ & 318 & 1 & 5 & 2.89 & 1.073 \\
Satisfaction in relations with superiors & 318 & 1 & 5 & 3.38 & 0.990 \\
Satisfaction in relations with colleagues & 318 & 2 & 5 & 3.87 & 0.954 \\
\hline
\end{tabular}

Source: Synthesis from questionnaires.

relationship (3.87 points); The lowest satisfaction rating score belongs to the factor "salaries and welfare" (2.34 points).

\subsection{Check the Reliability of the Scale}

The Cronbach's Alpha coefficient test result shows that all the coefficients are greater than 0.6 (Table 3), the correlation coefficient with the total variable of the observed variables are greater than 0.3 . This shows that research is appropriate and reliable. In 6 groups of factors with initial observation variable are 29 variables, remove one variable from the scale (TC4) because it has Cronbach's Alpha if the Item Deleted is greater than the Cronbach's Alpha of the scale. After removing one variable, the number of observations variables taken into the model is 28 variables.

\subsection{Factor Analysis EFA}

Using EFA factor analysis with Varimax rotation to analyze 28 observational variables 
Table 3. Cronbach's Alpha test result.

\begin{tabular}{lcccc}
\hline \multirow{2}{*}{ Scale } & \multicolumn{3}{c}{ The number of observation variable } & $\begin{array}{c}\text { Cronbach's } \\
\text { Alpha }\end{array}$ \\
\cline { 2 - 5 } 1. TC & 4 & 3 & 1 & 0.930 \\
2. DK & 5 & 5 & None & 0.916 \\
3.TL & 7 & 7 & None & 0.943 \\
4. DT & 4 & 4 & None & 0.906 \\
5. CT & 5 & 5 & None & 0.923 \\
6. DN & 4 & 4 & None & 0.904 \\
Total & $\mathbf{2 9}$ & $\mathbf{2 8}$ & $\mathbf{1}$ & \\
\hline
\end{tabular}

Source: Synthesis from test results.

after Cronbach's Alpha reliability test.

The results of the first analysis, because TL4 variable has 2 factors loading of 0.697 and 0.422 in 2 groups 1 and 2, the difference of 0.275 is less than 0.3 , it does not meet the conditions to ensure "Differentiated value": loading factor of the observed variable when uploading 2 factors must be over 0.3 , therefore, continue to remove the TL4 variable from the scale. The results of factor analysis after the removal of variables with loading factor less than 0.3 are as follows: (Table 4).

The results of the second analysis, at Eigenvalue value is 1.206 (greater than 1) with Principal Components variance and Varimax rotation, factor analysis extracted 6 factors from 27 observational variables with variance extraction of $80.803 \%$ ( $>50 \%)$ qualified. The KMO coefficient is $0.685(>0.5)$ shows that the analysis is meaningful. The value sig $=0.000<0.05$ indicates that the observed variables correlate each other in the overall and the EFA factor analysis is appropriate.

The process of factor analysis with the Eigenvalues value is $1.206(>1)$, the 27 observed variables are converged in 6 groups of factors: Salaries and welfare (TL); Relations with superiors (CT); Working conditions (DK); Relations with colleagues (DN); Training and promotion opportunities (DT); Nature of work (TC). Total variance extraction is $83.803 \%$, that means $83.8 \%$ of the fluctuation in data is explained by these six factors

\subsection{Analysis of Linear Correlation and Regression}

\subsubsection{Analysis of Linear Correlation}

From the result of factor analysis EFA, the authors use the linear correlation method "Pearson correlation" to assess the correlations relation between the factors in the model.

The results of the correlation analysis (Table 5) show that the correlation coefficients of the factors $(r)>0$, the sig value $<0.05$ indicates that the variables are linear correlation and statistically significant. With a $10 \%$ significance level, 
the independent variables in the model have a linear correlation relationship with the dependent variable, and the independent variables also have a relatively close linear relationship. This suggests that a separate consideration of the affect

Table 4. Factor analysis EFA result.

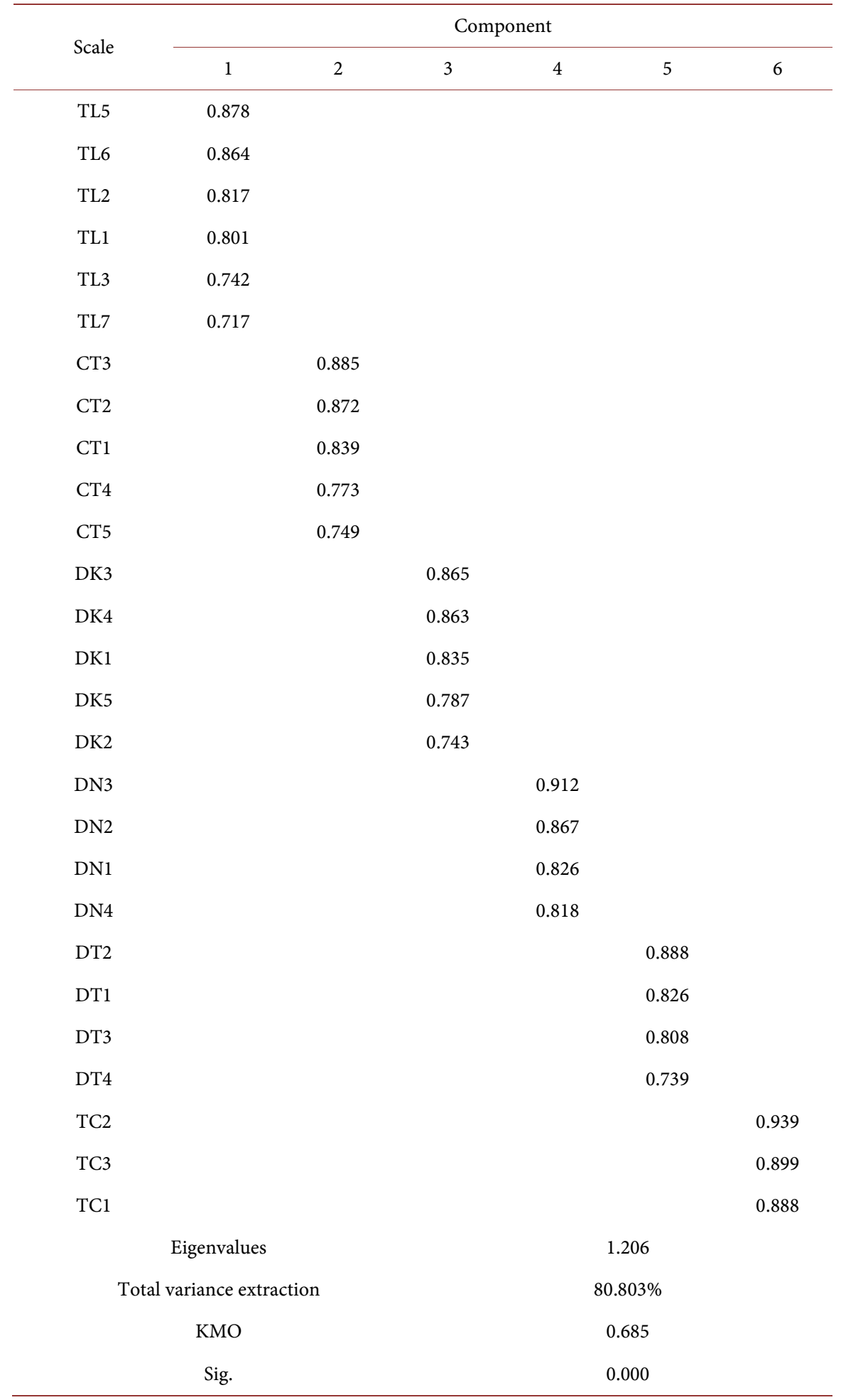

Source: Synthesis from test results. 
Table 5. Linear Correlation result.

\begin{tabular}{|c|c|c|c|c|c|c|c|c|}
\hline & & $\mathrm{HL}$ & TL & CT & DK & $\mathrm{DN}$ & DT & TC \\
\hline \multirow{3}{*}{$\mathrm{HL}$} & Pearson Correlation & 1 & $0.671^{* *}$ & $0.646^{* *}$ & $0.638^{\star *}$ & $0.591^{* *}$ & $0.668^{* *}$ & $0.487^{\star *}$ \\
\hline & Sig. (2-tailed) & & 0.000 & 0.000 & 0.000 & 0.000 & 0.000 & 0.000 \\
\hline & $\mathrm{N}$ & 318 & 318 & 318 & 318 & 318 & 318 & 318 \\
\hline \multirow{3}{*}{$\mathrm{TL}$} & Pearson Correlation & $0.671^{* *}$ & 1 & $0.413^{* *}$ & $0.511^{* *}$ & $0.291^{* *}$ & $0.448^{* *}$ & $0.256^{\star *}$ \\
\hline & Sig. (2-tailed) & 0.000 & & 0.000 & 0.000 & 0.000 & 0.000 & 0.000 \\
\hline & $\mathrm{N}$ & 318 & 318 & 318 & 318 & 318 & 318 & 318 \\
\hline \multirow{3}{*}{$\mathrm{CT}$} & Pearson Correlation & $0.646^{* *}$ & $0.413^{* *}$ & 1 & $0.265^{* *}$ & $0.356^{* *}$ & $0.475^{* *}$ & $0.165^{\star *}$ \\
\hline & Sig. (2-tailed) & 0.000 & 0.000 & & 0.000 & 0.000 & 0.000 & 0.003 \\
\hline & $\mathrm{N}$ & 318 & 318 & 318 & 318 & 318 & 318 & 318 \\
\hline \multirow{3}{*}{ DK } & Pearson Correlation & $0.638^{\star *}$ & $0.511^{* *}$ & $0.265^{* *}$ & 1 & $0.194^{* *}$ & $0.298^{* *}$ & $0.301^{\star *}$ \\
\hline & Sig. (2-tailed) & 0.000 & 0.000 & 0.000 & & 0.000 & 0.000 & 0.000 \\
\hline & $\mathrm{N}$ & 318 & 318 & 318 & 318 & 318 & 318 & 318 \\
\hline \multirow{3}{*}{ DN } & Pearson Correlation & $0.591^{\star *}$ & $0.291^{* *}$ & $0.356^{* *}$ & $0.194^{\star *}$ & 1 & $0.232^{\star *}$ & $0.209^{* *}$ \\
\hline & Sig. (2-tailed) & 0.000 & 0.000 & 0.000 & 0.000 & & 0.000 & 0.000 \\
\hline & $\mathrm{N}$ & 318 & 318 & 318 & 318 & 318 & 318 & 318 \\
\hline \multirow{3}{*}{ DT } & Pearson Correlation & $0.668^{* *}$ & $0.448^{* *}$ & $0.475^{* *}$ & $0.298^{* *}$ & $0.232^{\star *}$ & 1 & $0.350^{\star *}$ \\
\hline & Sig. (2-tailed) & 0.000 & 0.000 & 0.000 & 0.000 & 0.000 & & 0.000 \\
\hline & $\mathrm{N}$ & 318 & 318 & 318 & 318 & 318 & 318 & 318 \\
\hline \multirow{3}{*}{ TC } & Pearson Correlation & $0.487^{\star *}$ & $0.256^{* *}$ & $0.165^{* *}$ & $0.301^{\star *}$ & $0.209^{* *}$ & $0.350^{* *}$ & 1 \\
\hline & Sig. (2-tailed) & 0.000 & 0.000 & 0.003 & 0.000 & 0.000 & 0.000 & \\
\hline & $\mathrm{N}$ & 318 & 318 & 318 & 318 & 318 & 318 & 318 \\
\hline
\end{tabular}

**. Correlation is significant at the 0.01 level (2-tailed). Source: Synthesis from test results.

level of each independent variable on the regression model to the dependent variable is appropriate and will give accurate results.

\subsubsection{Regression Analysis}

Based on the results of the linear correlation analysis, the authors conducted a regression analysis to examine how is the impact of factors on the dependent variable.

Table 6, Regression analysis results include 3 table: Model Summary table; ANOVA variance analysis table and regression coefficients table.

The results from the Table 6, with Sig value $<0.05$, show that 6 independent variables have an affect on the dependent variable and the standardized coefficients beta shows the degree of influence of 6 independent variables on dependent variable.

In Model Summary table, the adjusted coefficient $\mathrm{R}^{2}=0.891$ indicates that the independent variables in the model can explain $89.1 \%$ of the variation of the dependent variable. 
Table 6. Regression analysis result.

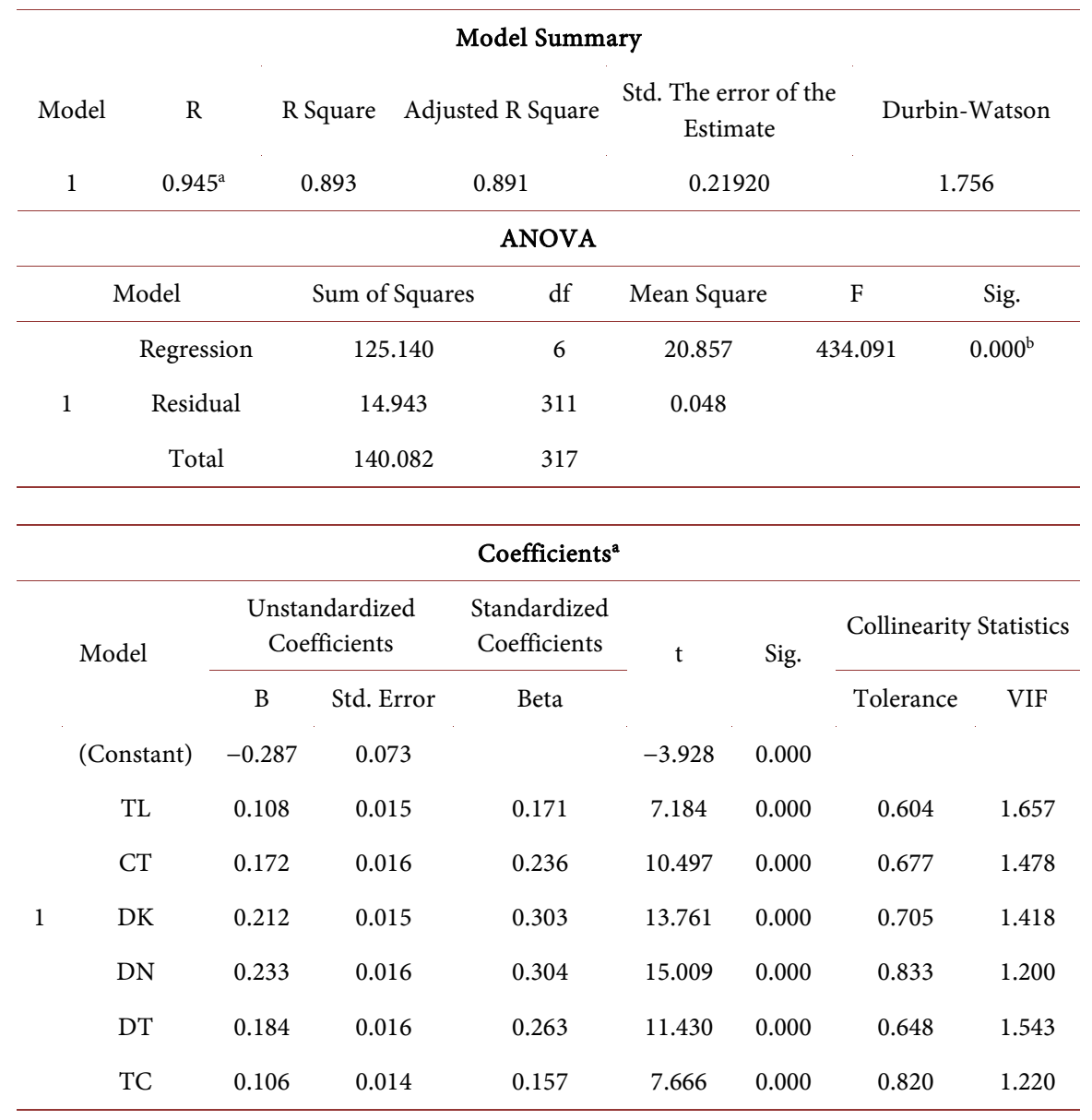

a. Dependent Variable: HL; Source: Synthesis from test results

In the ANOVA variance analysis table, the value $\mathrm{F}=434,091$; sig value $=0.000$ shows that the linear regression model is suitable for the data set and can be using.

In the regression coefficients table, the statistics coefficient Durbin-Watson = 1756 show that there is no correlation between the remainder. This means that the regression model does not violate the assumption of the independence of the variation. Magnification coefficient (VIF) with the value of less than 10 indicates that the regression model does not violate multicollinearity phenomenon (independent variables are strongly correlated with each other).

From the results of regression analysis, the authors set up a linear regression equation that evaluates the impact of independent factors on the dependent variable "Employee satisfaction in work" as follows:

$$
\mathrm{HL}=0.171 \mathrm{TL}+0.236 \mathrm{CT}+0.303 \mathrm{DK}+0.304 \mathrm{DN}+0.26 \mathrm{DT}+0.157 \mathrm{TC}
$$

Through the data shown in the linear regression equation, it can be seen that under the condition the other factors unchanged, if the factor "Salaries and welfare" (TL) increases by one unit, the "Employee satisfaction in work" increases by 0.171 units; The factor "Relations with superiors" (CT) goes up one unit lead 
to the change of variable "Employee satisfaction in work" increases by 0.236 units; The factor "Working conditions" (DK) rises one unit, the change of variable "Employee satisfaction in work" increases by 0.303 units; The factor "Relations with colleagues" (DN) increases one unit, the change of variable "Employee satisfaction in work" rises by 0.304 units; The factor "Training and promotion opportunities" (DT) rises one unit, the change of variable "Employee satisfaction in work" increases by 0.263 units; The factor "Nature of work" (TC) increases one unit, the change of variable "Employee satisfaction in work" increases by 0.157 units

\section{Verify the Differential Impact of Personal Factor}

Test the differential impact of gender factor on satisfaction in work, because this factor has only two values so can be used the test "Independent-Sample T-test". The results show that: The Sig value at Levene's Test $=0.250>0.05$ indicates the variance between the male and female genders is uniform (no difference) and can use the sig T-Test at the line "Equal variances assumed". At the line "Equal variances assumed", Sig value $=0.019>0.05$, so we can conclude: There is a statistically significant difference in the satisfaction in work of employees with a different gender (Table 7).

Determine the impacts between groups of workers with different age on job satisfaction, the authors use the One-Way ANOVA test. In the test results, consider the value in the table: "Test of Homogeneity of Variances", Sig value of Levene Statistic $=0.000<0.05$, looking at the results of Post Hoc test with sig value $=0.021<0.05$, it can be concluded: There are statistically significant differences in job satisfaction of workers of different ages.

Determine different impacts among groups of workers with different seniority on job satisfaction, the authors use the One-Way ANOVA test. In the test results, consider the value in the table: “Test of Homogeneity of Variances", Sig value of Levene Statistic $=0.026<0.05$, looking at the results of Post Hoc test with sig value $=0.017<0.05$, it can be concluded: There are statistically significant differences in job satisfaction of workers with different seniority.

Table 7. Result of Independence-Sample T-test.

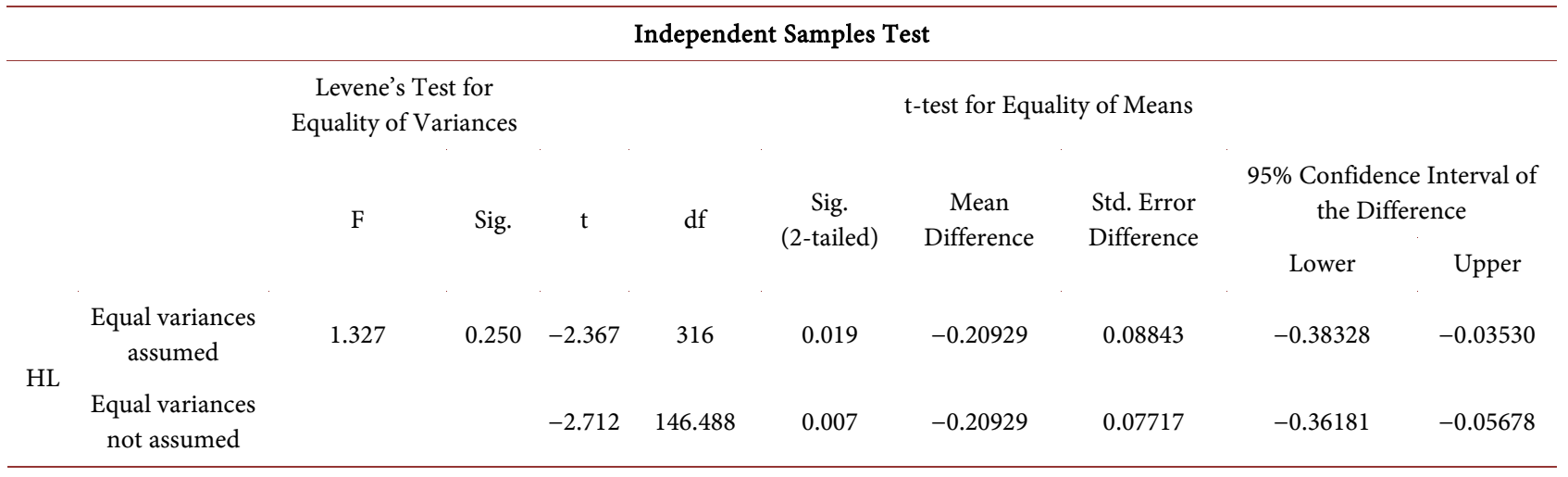

Source: Result from the regression analysis of the authors. 


\section{Conclusions and Recommendations}

\subsection{Conclusions}

The research results show that the job satisfaction level of workers reached an average level of 3.15 point. Specifically: $30.2 \%$ of surveyed people answer at the level from 1 - 3 points; $69.8 \%$ of surveyed people have a level from 4 - 5 points.

Employee satisfaction with aspects of the job is arranged according to the point of assessment of average satisfaction with the rating scale from 1 being the lowest to 5 being the highest.

1) The factor "Salaries and welfare" has an impact level of $17.10 \%$; the average satisfaction level was only 2.34 , of which $60.4 \%$ of the surveyed people had the level of consent from 1 to $3 ; 39.6 \%$ of surveyed people have a level of consent from 4 - 5 point, indicating that workers are not satisfied with wages and welfare at the enterprise.

2) The factor "Training and promotion opportunities" has an effect of $26.3 \%$. The average satisfaction level was 2.89 , of which $63.3 \%$ of the surveyed people had the level from 1 to $3 ; 37.7 \%$ of surveyed people have a level of consent $4-5$. This shows that employees do not appreciate and are not satisfied with the opportunity to be trained and promoted at the enterprise.

3) The factor "Working conditions" has an impact level of $30.3 \%$; the average satisfaction level is 2.89 , of which $49.1 \%$ of the surveyed people had a level of consent from 1 to 3 meanwhile $49.9 \%$ of surveyed people have the level of consent from 4 - 5. According to the results of quantitative analysis, this factor has quite a large impact but the survey shows that workers are not satisfied with the working conditions at the enterprise.

4) The factor "Relations with superiors" has an effect of $23.6 \%$; the average level of satisfaction is 3.38 , of which $24.5 \%$ of the surveyed people have a level of consent from 1 to 3 and $75.5 \%$ have a level of consent from $4-5$. The average satisfaction level of 3.38 points indicates that workers are relatively satisfied in the relationship with their direct manager.

5) The factor "Nature of work" has an impact level of $15.7 \%$; the average satisfaction level is 3.51 , of which $37.7 \%$ of the respondents had a level of consent from 1 to $3 ; 63.3 \%$ have the level of consent from $4-5$. This shows that although the characteristics of the garment industry are quite hard, in line with the worker's qualifications and capabilities, the impact of this factor is not high but the workers are quite satisfied with their current job.

6) The factor "Relations with colleagues" has an impact level of 30.4\%; the average satisfaction level is 3.87 , of which $11.3 \%$ of the surveyed people had a level of consent from 1 to $3 ; 89.7 \%$ have the level of consent from $4-5$. This factor has the highest impact and the workers are quite satisfied with the co-worker relationship. This shows there is a close sticking between employees in the enterprise.

\subsection{Recommendations}

Firstly, in terms of salary and welfare regime, the company needs to arrange and 
use labor in a reasonable manner, clearly identify the qualifications and competencies of workers and the complexity of the work to assign the right people and the right jobs, from which evaluate performance work and pay exactly and fairly salary according to labor results. At the same time, further, expand the welfare policy for employees.

Secondly, on the "relationship with superiors", build and implement democratic regulations at the departments as well as whole company; set up reporting channels and increase information exchange so that employees can easily share, report timely and receive the attention and assistance of the higher leaders to solve the work quickly as well as without difficulties in communicating and exchanging with the superiors. Thereby increase understanding between superiors and subordinates.

Thirdly, the factor "relations with colleagues", the company needs to continue to promote the values of the corporate culture that has been created. Organizing cultural exchanges, arts, and sports among departments, thereby enhance the solidarity between employees and bring about a spirit of refreshment, health, and physicality better for employees. Building a friendly and cooperative working atmosphere among individual employees.

Fourthly, on the "working conditions" factor, it is necessary to replace the old, broken or outdated equipment so that workers can easily use and improve the work effectively. Enhance the sense of law observance, abiding by labor safety and hygiene rules to increase labor productivity, working ability and ensure health and safety for workers.

Fifthly, regarding the factor "Training and promotion opportunities", it is necessary to focus on and spend time on training and improving skills for employees. The current reality is that workers spend too much time on their work but lack the time for skills training. Create conditions for qualified workers can be promotion, clear and reasonable promotion policies, ensure fairness among workers.

Sixth, about the factor "Nature of work", employees always need to affirm and perfect themselves at work. Therefore, it is necessary to clearly identify and show employees the role of work, the level of contribution, the importance of their work to the company. This will help employees to confirm their role, understand the work they are doing and create motivation to work better. Creating excitement in the work by the way the company has just performed the rewarding of employees and expressed the company's interest in the employees, create trust in the employees.

This study aims to identify and evaluate the factors affecting on job satisfaction of workers who are working in the garment industry. These groups of factors are measured through 6 independent variables representing 27 observed variables. However, due to time constraints, this study has not mentioned the impact of employment position factors on the satisfaction of workers because in textile enterprises, there are many different job positions, each individual at each job position will have different satisfaction levels. This is the limitation of this 
study, hopefully the next studies will analyze and evaluate more deeply on the level of influence of the job position factor on the satisfaction in work of the workers.

\section{Conflicts of Interest}

The authors declare no conflicts of interest regarding the publication of this paper.

\section{References}

[1] Vietnam State Audit (2018) Analyzing and Controlling Risks Due to Labor Fluctuations in Vietnamese Garment Enterprises. Journal of Auditing Studies. http://www.khoahockiemtoan.vn

[2] Herzberg, F., Mausner, B. and Snyderman, B.B. (1959) The Motivation to Work. John Wiley \& Sons, New York.

[3] Vroom, V.H. (1964) Work and Motivation. Wiley, New York.

[4] Maslow, A.H. (1954) Motivation and Personality. Harper and Row, New York.

[5] Adams, J.S. (1963) Toward an Understanding of Inequity. Journal of Abnormal and Social Psychology, 67, 422-436. https://doi.org/10.1037/h0040968

[6] McClelland, D.C. (1988) Human Motivation. Cambridge University Press.

[7] Smith, P.C., Kendall, L. and Hulin, C.L. (1969) The Measurement of Satisfaction in Work and Retirement. Rand McNally, Chicago.

[8] Dung, T.K (2005) Measure the Level of Satisfaction with the Job in the Context of Vietnam. Science and Technology Development Journal, 8, 1-9.

[9] Comrey, A.L. and Lee, H.B. (1992) The First Course in Factor Analysis. 2nd Edition, Lawrence Erlbaum Associates, Hillsdale.

[10] Trong, H. and Ngoc, C.N.M. (2008) Research Data Analysis with SPSS. Vol. 1, Hong Duc Publisher, Ho Chi Minh City.

https://sachvui.com/ebook/phan-tich-du-lieu-nghien-cuu-voi-spss-tap-1-hoang-tro ng-chu-nguyen-mong-ngoc.857.html 